\title{
Effects of 4A Zeolite Additions on the Structure and Performance of LDPE Blend Microfiltration Membrane through Thermally Induced Phase Separation Method
}

\author{
Jin Gü, Aonan Lai, Jun Zhang, Yunxiang Baï, Chunfang Zhang* and Yuping Sun*
}

The Key Laboratory of Food Colloids and Biotechnology, Ministry of Education, School of Chemical and Materials Engineering, Jiangnan University, Wuxi 214122, China

\begin{abstract}
Microfiltration membranes, 4A zeolite/LDPE, were prepared by blending low density polyethylene (LDPE) and 4A zeolite through thermally induced phase separation (TIPS) process with diphenyl ether (DPE) as diluent. The effects of $4 \mathrm{~A}$ zeolite loading on the pore structure and water permeation performance of the 4A zeolite/LDPE blend membranes were investigated. The incorporation of $4 \mathrm{~A}$ zeolite particles greatly enhanced the connectivity of membrane pores, the pore size, and thus the water flux of $4 \mathrm{~A}$ zeolite/LDPE blend membranes due to the gradually stronger DPE-zeolite affinity with the increase of the $4 \mathrm{~A}$ zeolite loading. The water flux increased from 0 of LDPE control membrane to $87 \mathrm{~L} / \mathrm{m}^{2} \mathrm{~h}$ of $4 \mathrm{~A}$ zeolite/LDPE blend membrane with $4 \mathrm{~A}$ zeolite loading of $10 \mathrm{wt} \%$. In addition, increasing the DPE content and cooling bath temperature is in favor of the water flux of $4 \mathrm{~A}$ zeolite/LDPE blend membranes.
\end{abstract}

Keywords: Low density polyethylene, 4A zeolite, Microporous membrane, Thermally induced phase separation.

\section{INTRODUCTION}

With the expanding application of membrane separation technology in chemical industry, urgent needs of strategies to increase the performance of membrane materials, such as precise control of membrane structures, cost reduction of membrane preparation and improvement of membrane strength, has prompted actions of many researchers [1, 2]. Low density polyethylene (LDPE) is an outstanding membrane material because of its nontoxicity, excellent mechanical strength, physical and chemical stability, high anti-degradation as well as low cost [3]. Unfortunately, up to now, LDPE has not been successfully fabricated into microfiltration membranes in industry as other polyolefins like high density polyethylene (HDPE), poly polyvinylidene fluoride (PVDF), polypropylene (PP) and so on. This is mainly due to its lower crystallinity and the lackage of solvent for LDPE at room temperature, both the conventional methods of melt-spinning \& stretching (MS-S) and immersion precipitation (IP) cannot be used to prepare LDPE membrane. Thermally induced phase separation (TIPS) [4-8], based on the dependence of polymer solubility on temperature, offers an attractive way to prepare LDPE porous membranes where a homogeneous LDPE solution is formed by dissolving

\footnotetext{
*Address corresponding to this author at the Key Laboratory of Food Colloids and Biotechnology, Ministry of Education, School of Chemical and Materials Engineering, Jiangnan University, Wuxi 214122, China; Tel: 86-0510-85917090; Fax: 86-0510-85917763;

E-mail: sunyp2003@yahoo.com.cn

"Co-Authors

Jin Gu: jingugu@yahoo.com.cn

Yunxiang Bai: baisir223@163.com

Chunfang Zhang: zcf326@163.com
}

LDPE in diluent above the melting temperature of pure LDPE, and then phase separation is induced by cooling the LDPE solution. Zhang et al. [9, 10] have prepared hydrophobic polyethylene microporous membranes via the liquid-liquid TIPS process using the system of LDPE/diphenyl ether (DPE) and they found that, with the increase of LDPE mass fraction, the pore size decreased and the membranes microstructure varied due to different phase separation mechanisms. Unfortunately, the LDPE membranes prepared via TIPS suffer from extremely low permeability due to the poor pore connectivity. In this regard, membrane modification is expected to bring desired changes in structure and permeability to LDPE membrane without losing inherent characteristics.

Compared to the pure polymer membrane, the polymer/inorganic particle blend membrane has the advantages of pore structure tunability, better mechanical strength and significantly improved antifouling performance $[11,12]$. Different with other commonly used inorganic particles, such as calcium carbonate $\left(\mathrm{CaCO}_{3}\right)$ [13], silica $\left(\mathrm{SiO}_{2}\right)$ [14], aluminium oxide $\left(\mathrm{Al}_{2} \mathrm{O}_{3}\right)$ [15] and titanium dioxide $\left(\mathrm{TiO}_{2}\right)$ [16], 4A zeolite possesses the merits of large surface area, high thermal stability and good adsorption ability, and so on. For example, Funk et al. [17] prepared isotactic polypropylene/zeolite blend membrane via TIPS method. They found that the incorporation of zeolite particles played a very important role in the growth of diluent-rich droplets during liquid-liquid TIPS process and the ultimate pore size of the final membranes.

Therefore, in the present study, to improve the structure and permeability of LDPE, nano-sized 4A 
zeolite particles was used as filler to prepare $4 \mathrm{~A}$ zeolite/LDPE blend membranes via TIPS process. Specifically, this study focuses on the effect of $4 \mathrm{~A}$ zeolite loading on the morphology, mechanical and thermal properties of $4 \mathrm{~A}$ zeolite/LDPE blend membranes. In addition, the effects of the composition of the initial casting solution and the temperature of cooling bath on the permeability of $4 \mathrm{~A}$ zeolite/LDPE blend membranes were also investigated.

\section{EXPERIMENTAL}

\section{Materials}

Low density polyethylene (LDPE) with melting index of $1.5 \mathrm{~g} / 10 \mathrm{~min}$ was supplied by Petrochina Daqing Petrochemical Company, Heilongjiang China. 4A zeolite with average particle size of $3.5 \mu \mathrm{m}$ was purchased from Sigma Aldrich, USA. To remove water adsorbed on the particle surface, $4 \mathrm{~A}$ zeolite powder was held at $200{ }^{\circ} \mathrm{C}$ in a vacuum oven for $48 \mathrm{~h}$ and then cooled down to room temperature in a dryer before the membrane preparation. Diphenyl ether (DPE), cyclohexane and ethanol were obtained from Sinopharm Chemical Reagent Co. Ltd., China and used and used without further purification.

\section{Preparation of Membranes}

The premixed LDPE/DPE blend systems were melted for $1 \mathrm{~h}$ at $170{ }^{\circ} \mathrm{C}$ in a glass vessel with stirring. After that, certain amounts of $4 \mathrm{~A}$ zeolite were added into the LDPE/DPE solution and the mixtures were further melt for at least $5 \mathrm{~h}$ until homogeneous solution were formed. After degassed to remove bubble, the mixtures were quenched in liquid nitrogen and the solid LDPE/zeolite/DPE blend samples were obtained.

The process of membrane preparation was carried out as described in our previous work [18]. Briefly, a portion of the above sample was placed between a pair of stainless steel plate. A Teflon film with a square opening in the center was inserted between them to adjust the thickness of membranes to about $100 \mu \mathrm{m}$. The sample was heated up to $170{ }^{\circ} \mathrm{C}$ for 3 minutes on a heater and then pressed into thin film. After that, the stainless steel plate containing the film was taken out quickly and quenched in a cooling bath at different temperature for 10 minutes. The diluent in the film was extracted by immersing the membrane in ethanol for 48 hours. The final membrane was dried under vacuum at room temperature for $24 \mathrm{hr}$.

\section{Scanning Electron Microscopy (SEM)}

The surface and cross-section (fractured in liquid nitrogen) morphologies of $4 \mathrm{~A}$ zeolite/LDPE membranes were inspected by a Hitachi $\$ 4800$ scanning electron microscope (SEM) after being coated with gold, the final gold thickness on the membrane is $15 \mathrm{~nm}$.

\section{Differential Scanning Calorimetry (DSC)}

The crystallization of $4 \mathrm{~A}$ zeolite/LDPE membranes was characterized by DSC (PerkinElmer, DSC-7) at a heating rate of $10{ }^{\circ} \mathrm{C} / \mathrm{min}$. The crystallinity $\left(X_{c}\right)$ was calculated based on equation (1) from the DSC curves [14]:

$X_{c}=\frac{\Delta H / \phi}{\Delta H_{m}} \times 100 \%$

where $\Delta H_{\mathrm{m}}$ is the melting enthalpy for a $100 \%$ crystalline LDPE and the value is $273 \mathrm{~J} / \mathrm{g}$ [19], $\Delta H$ is the melting enthalpy of the prepared membrane measured in DSC and $\phi$ is the weight fraction of LDPE in 4A zeolite/LDPE blend membranes.

\section{Mechanical Properties Studies}

Stretching testing of $4 \mathrm{~A}$ zeolite/LDPE membranes were performed at room temperature using an electronic universal testing machine (WCT-10, Shenzhen, China) with a crosshead speed of 5 $\mathrm{mm} / \mathrm{min}$. The width and length of the sample was 10 $\mathrm{mm}$ and $50 \mathrm{~mm}$, respectively [20]. Five measurements were done for each sample to get the average value.

\section{Static Contact Angle Measurement}

Static contact angles for water of $4 \mathrm{~A}$ zeolite/LDPE membranes were measured by sessile drop method [21] using a Contact Angle Meter (OCA 20, Dataphysics Instruments GmbH Germany) at $25{ }^{\circ} \mathrm{C}$ and about $65 \%$ relative humidity. The volume of the ultrapure water drop used was always $2 \mu \mathrm{L}$. All reported values were the average of at least eight measurements taken at different locations of the membrane surface and had a typical mean error of $\pm 1^{\circ}$.

\section{Pure Water Flux and Porosity}

Water flux experiments were performed at $25^{\circ} \mathrm{C}$ on a dead-end membrane evaluation cell with an effective filtration area of $12 \mathrm{~cm}^{2}$, as shown in Figure 1. Water permeation tests cannot be run on a LDPE membrane without first pre-wetting the membrane because LDPE 
is a hydrophobic material. So, the water permeation experiments were carried out using a two-step process [22]. That is, after being pre-wetted with an ethanol/water solution ( $85 \mathrm{wt} \%$, ethanol) for $30 \mathrm{~min}$, the 4A zeolite/LDPE membrane sample was stabilized at $0.15 \mathrm{MPa}$ for at least $30 \mathrm{~min}$ with deionized water. Then the operation pressure was reduced to $0.1 \mathrm{MPa}$ and the water flux was obtained from the volume of the permeated water with $1 \mathrm{~h}$. The flux of pure water $(F)$ was calculated as following equation:

$$
F=\frac{V}{A t}
$$

where $V$ is the volume of the permeated water during the experiment $(\mathrm{L}), \quad A$ represents the effective membrane area $\left(\mathrm{m}^{2}\right)$, and $t$ denotes the operation time (h). Three measurements were done for each sample to get the average value.

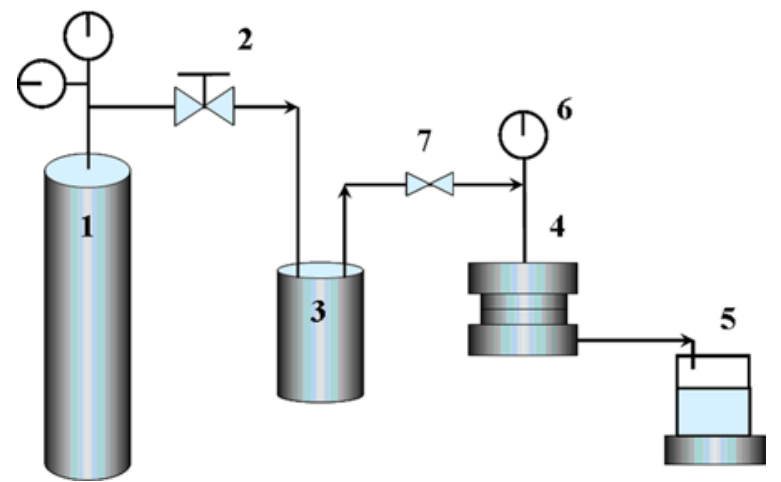

Figure 1: Schematic illustration of the filtration apparatus: (1) nitrogen cylinder; (2) precise value; (3) water reservoir; (4) filtration cell; (5) beaker; (6) pressure gauge; (7) value.

The membrane porosity $(\varepsilon)$ is defined as the pores volume divided by the total volume of the porous membrane. It can be determined by gravimetric method and calculated as equation (3) [14]:

$\varepsilon(\%)=\left(1-\frac{\rho_{f}}{\rho_{p}}\right) \times 100 \%$

where $\rho_{\mathrm{f}}$ is membrane apparent density $\left(\mathrm{kg} / \mathrm{m}^{3}\right.$, determined by gravimetric method), $\rho_{\mathrm{p}}$ is LDPE density $\left(0.924 \mathrm{~kg} / \mathrm{m}^{3}\right)$. The reported data were the average values of triplicate samples for each membrane.

\section{RESULTS AND DISCUSSION}

\section{Effect of 4A Zeolite Loading on the Morphology and Performance of 4A Zeolite/LDPE Blend Membranes}

4A zeolite/LDPE membranes were formed at a fixed cooling bath temperature of $25^{\circ} \mathrm{C}$ and LDPE:DPE ratio of $1: 3(\mathrm{w} / \mathrm{w})$ with the $4 A$ zeolite loading of $0,2,6$ and 10 $w t \%$ according to the whole weight of a $4 \mathrm{~A}$ zeolite/LDPE/DPE mixture. That means the weight ratios of 4A zeolite:LDPE:DPE are 0:25:75, $2: 24.5: 73.5, \quad 4: 24: 72, \quad 6: 23.5: 70.5$ and $10: 22.5: 67.5$ $(\mathrm{w} / \mathrm{w} / \mathrm{w})$, respectively.

\section{Morphology}

The morphology of $4 \mathrm{~A}$ zeolite/LDPE membranes were determined by SEM from both the surface and cross-section, as shown in Figure 2. Both the pure LDPE and 4A zeolite/LDPE blend membranes showed the typical symmetrical morphology with cellular pores which resulted typically from liquid-liquid phase separation via nucleation and growth of diluent-rich droplet. In addition, zeolite obviously plays a very important role in the pore size of 4A zeolite/LDPE blend membranes. The cellular pore size of $4 \mathrm{~A}$ zeolite/LDPE blend membrane decreased initially and then increased with the increase of $4 \mathrm{~A}$ zeolite loading. This observation can be attributed to the fact that the affinity among polymer, $4 \mathrm{~A}$ zeolite and DPE changed with the increase of $4 \mathrm{~A}$ zeolite loading in the LDPE/zeolite/DPE system. The LDPE-zeolite and DPE-zeolite interactions were not quantified in this study, however, SEM micrographs taken during this study clearly showed the affinities changes, the similar phenomena were also observed by Douglas R. Lloyd and co-workers when they prepared 4A zeolite/polypropylene blend microfiltration membranes [17]. At low 4A zeolite loading (2 wt\%), the 4A zeolite particles were surrounded by voids, which indicated a strong DPEzeolite affinity. This strong DPE-zeolite affinity resulted in the migration of DPE to the $4 \mathrm{~A}$ zeolite particle surface during the phase separation process. Consequently, the increase of polymer concentration in a 4A zeolite-polymer-diluent system brought about a thicker polymer solution which would slow down the phase separation rates, in another word, the droplet growth rates. Thus the resulted pores of $4 \mathrm{~A}$ zeolite/LDPE membranes should be smaller after the diluent was extracted out. Conversely, at high 4A zeolite loading ( $6 \mathrm{wt} \%)$, the $4 \mathrm{~A}$ zeolite was coated with polymer, which can be attributed to the fact that the polymer-zeolite affinity is stronger than that of DPEzeolite. This strong polymer-zeolite affinity resulted in the dissolved polymer migrating to the $4 \mathrm{~A}$ zeolite particle surface during the phase separation process. Therefore, the bulk polymer concentration and viscosity decreased and droplet growth rates increase [17]. This is why the pore size of $4 \mathrm{~A}$ zeolite/LDPE blend membrane with 6 wt $\% 4 \mathrm{~A}$ zeolite loading is larger than 


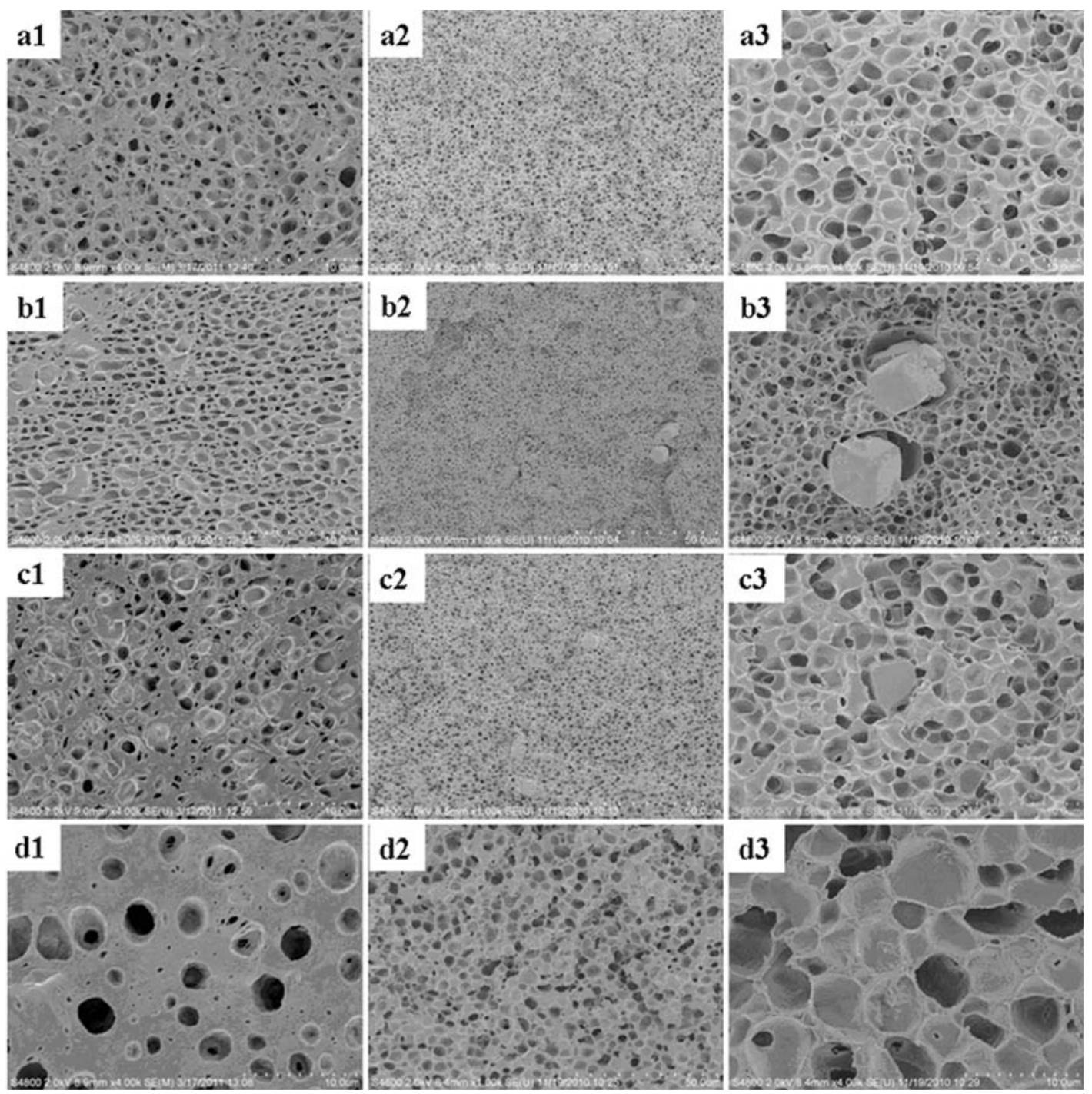

Figure 2: Effect of $4 \mathrm{~A}$ zeolite loading on the morphology of $4 \mathrm{~A}$ zeolite/LDPE blend membranes (a) $0 \%$, (b) $2 \%$, (c) $6 \%$ and (d) $10 \%$. 1, 2, 3 represented surface $4000 \times$, cross section 1000x and cross section $4000 \times$, respectively.

that of the pure LDPE membrane. As the $4 \mathrm{~A}$ zeolite loading further increased (10 wt\%), the stronger polymer-zeolite affinity make more polymer migrate out of the bulk solution to form the compact coating at the zeolite surface. As a result, the $4 \mathrm{~A}$ zeolite is buried deep in the matrix of LDPE segments as can be seen from Figure 2 (d4). Meanwhile, the pore size of $4 \mathrm{~A}$ zeolite/LDPE blend membrane with 10 wt\% 4A zeolite is the largest among all the $4 \mathrm{~A}$ zeolite/LDPE membranes.

\section{Thermal and Crystalline Properties}

The melting temperature and crystallinity of $4 \mathrm{~A}$ zeolite/LDPE blend membranes with different $4 \mathrm{~A}$ zeolite loading are shown in Figure 3 . It can be seen that the crystallinity of $4 \mathrm{~A}$ zeolite/LDPE blend membrane increased initially, passed through a maximum and then dropped down with increasing $4 \mathrm{~A}$ zeolite loading. The observation can be attributed to affinity change in the LDPE/zeolite/DPE system again, that is, the variety of $4 \mathrm{~A}$ zeolite loading brought about the affinity change among LDPE, 4A zeolite and DPE. As for low $4 \mathrm{~A}$ zeolite loading, the affinity of DPE-zeolite is stronger than that of LDPE-zeolite [17]. It is hypothesized that the strong DPE-zeolite affinity resulted in an increasing polymer concentration in the bulk solution prior to and during phase separation due to diluent migration. More LDPE in solution facilitates the formation of crystal nuclei, which in turn increase the crystallinity of membrane. Conversely, the LDPEzeolite affinity is greater than the DPE-zeolite affinity at high 4A zeolite loading, which induces a decreasing polymer concentration in the bulk solution. Less LDPE in solution brought about the decrease of the crystallinity. 
In addition, according to Figure 3 , the melting temperatures of $4 \mathrm{~A}$ zeolite/LDPE blend membrane increase with increasing the $4 \mathrm{~A}$ zeolite loading. The presence of $4 \mathrm{~A}$ zeolite particles in the LDPE/4A zeolite/DPE system can be regarded as the heterogeneous nucleating agent during the formation of 4A zeolite/LDPE blend membranes [14]. Consequently, LDPE at the LDPE/4A zeolite/DPE system with higher $4 \mathrm{~A}$ zeolite loading inclines to crystallize at higher temperature compared to that with lower $4 \mathrm{~A}$ zeolite loading, thus leading to a higher melting temperature of the corresponding 4A zeolite/LDPE blend membrane.

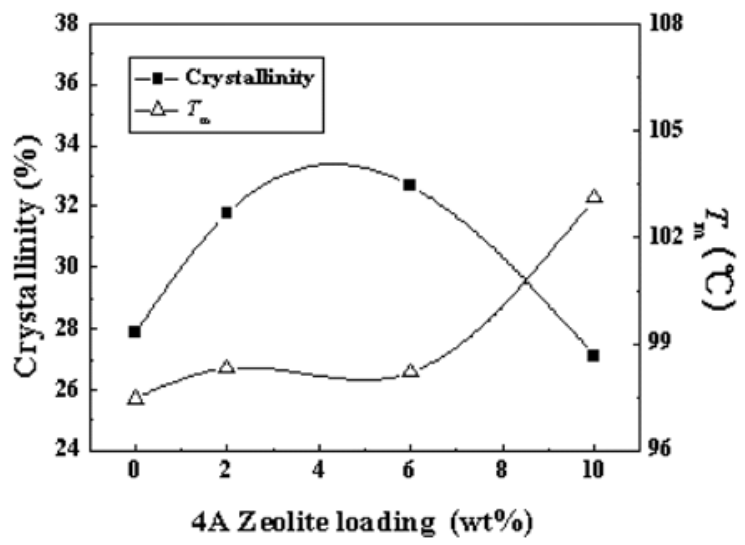

Figure 3: Effect of $4 \mathrm{~A}$ zeolite loading on melting temperature and crystallinity of $4 \mathrm{~A}$ zeolite/LDPE blend membranes.

\section{Mechanical Properties}

Figure 4 showed the effect of $4 \mathrm{~A}$ zeolite loading on the mechanical strength of the 4A zeolite/LDPE blend membranes. Both the tensile strength and elongationat-break increased with the enhancement of $4 \mathrm{~A}$ zeolite loading. These behaviors indicate that more $4 \mathrm{~A}$ zeolite in LDPE/4A zeolite/DPE system can result in a better mechanical property of $4 \mathrm{~A}$ zeolite/LDPE blend membrane at the studied $4 \mathrm{~A}$ zeolite loading range in this paper. 4A zeolite particles could be regarded as physical cross-linkages in the 4A zeolite/LDPE blend membranes [17]. So a higher $4 A$ zeolite loading is favor to the mechanical property of $4 \mathrm{~A}$ zeolite/LDPE blend membranes.

Nonetheless, a 4A zeolite loading range of $0-10 w t \%$ was chosen in this report because preliminary experiments indicated that it is too difficult to process LDPE/4A zeolite/DPE samples with $4 \mathrm{~A}$ zeolite loading higher than $10 \mathrm{wt} \%$ due to the poor dispersibility of $4 \mathrm{~A}$ zeolite in LDPE/DPE system.

\section{Hydrophilicity}

Generally, the introduction of hydrophilic inorganic particles to hydrophobic polymer membrane can

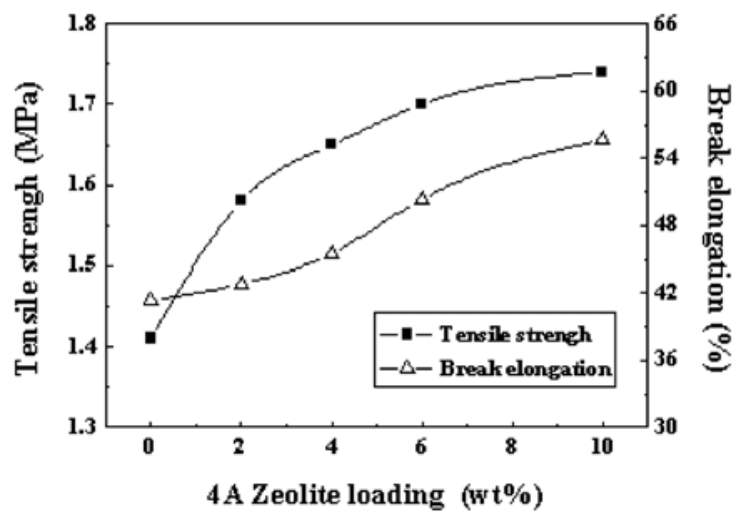

Figure 4: Effect of $4 \mathrm{~A}$ zeolite loading on the mechanical properties of $4 \mathrm{~A}$ zeolite/LDPE blend membranes.

improve the hydrophilicity of the membrane surface and pore walls [23]. The adsorbed foulants on the polymer/inorganic particles blend membranes could be more readily dislodged by shear force than those on a pure polymer membrane, and thus improving the antifouling performance of the membranes [24]. Since 4A zeolite used in this work is of very hydrophilic [25], an additional measurement of contact angle was performed to investigate the effect of $4 \mathrm{~A}$ zeolite loading on the membrane hydrophilicity. Figure 5 shows the values of static water contact angle of $4 \mathrm{~A}$ zeolite/LDPE blend membranes with different $4 \mathrm{~A}$ zeolite loading. It can be seen that all of $4 \mathrm{~A}$ zeolite/LDPE blend membranes are very hydrophobic. With increasing $4 \mathrm{~A}$ zeolite loading from 0 to $10 \mathrm{wt} \%$, the contact angle of 4A zeolite/LDPE blend membranes declines slightly from $133.4^{\circ}$ to $122^{\circ}$. The decrease of contact angle can be attributed to the hydrophilicity of zeolite powder, which results in the improvement of hydrophilic properties with increasing of $4 \mathrm{~A}$ zeolite loading for $4 \mathrm{~A}$ zeolite/LDPE blend membranes.

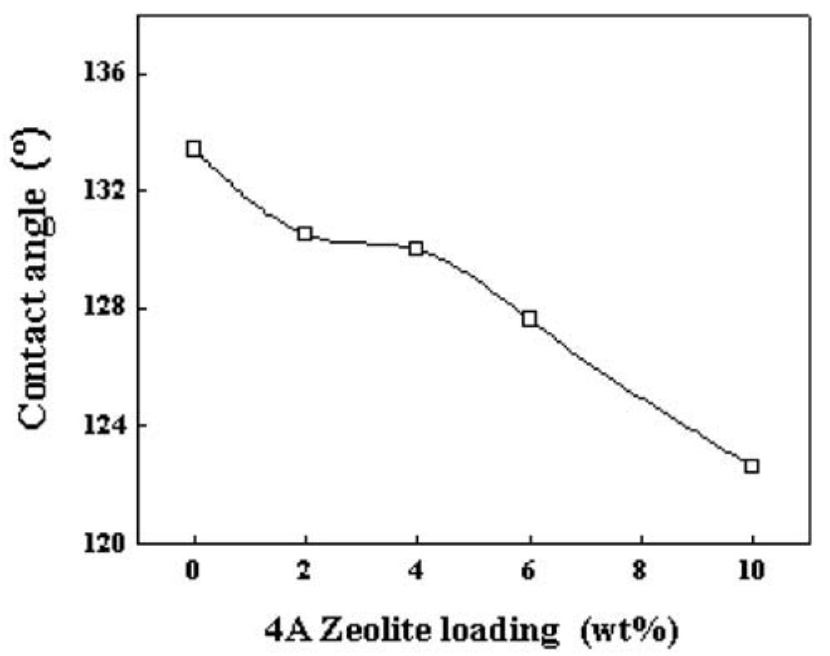

Figure 5: Effect of $4 \mathrm{~A}$ zeolite loading on the contact angle of 4A zeolite/LDPE blend membranes. 


\section{Water Flux}

The water flux and porosity of $4 \mathrm{~A}$ zeolite/LDPE blend membranes with different $4 \mathrm{~A}$ zeolite loading were shown in Figure 6. It could be seen that the water flux demonstrated uptrend, while the porosity showed downtrend, with increasing 4A zeolite loading. Generally, the water flux of a porous membrane is depended on its porosity, pore size, the connectivity of membrane pores and the hydrophilicity of surface. Among them, the connectivity of membrane pores is the vital factor to higher water flux regardless the porosity and the pore size is larger or not. From the SEM images (Figure 2), we can see that the higher 4A zeolite loading result in the larger pore sizes in blend membrane, which partly contributed to the higher water flux of $4 \mathrm{~A}$ zeolite/LDPE blend membranes. On the other hand, the hydrophilicity of the $4 \mathrm{~A}$ zeolite/LDPE blend membranes is slightly improved by the addition of $4 \mathrm{~A}$ zeolite (see Figure 5). More important, the connectivity of pores of the 4A zeolite/LDPE blend membranes is improved. Therefore, the permeability of the 4A zeolite/LDPE blend membranes were greatly enhanced with the increase of $4 \mathrm{~A}$ zeolite loading although the porosity of membranes decreased, as shown in Figure 6.

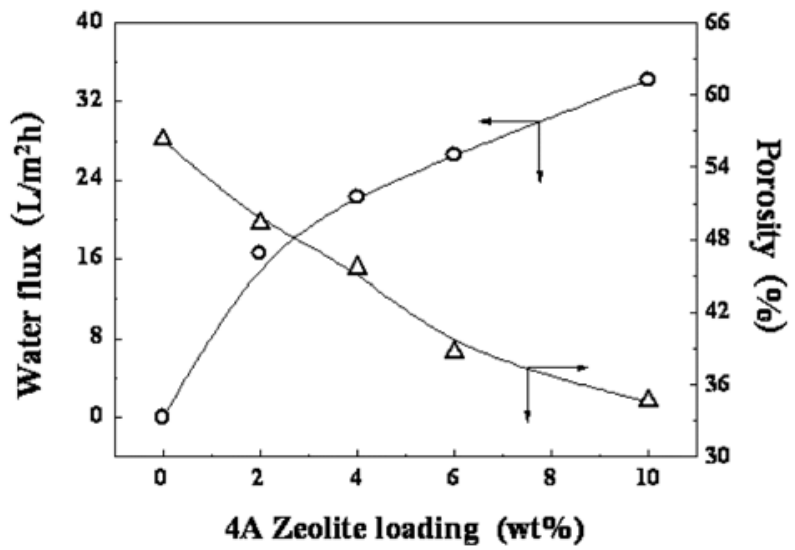

Figure 6: Effect of $4 \mathrm{~A}$ zeolite loading on the water flux and porosity of $4 \mathrm{~A}$ zeolite/LDPE blend membranes, the applied pressure for water flux measurements is $0.1 \mathrm{MPa}$.

\section{Effect of DPE Content on Water Flux of 4A Zeolite/LDPE Blend Membranes}

The effect of DPE content on the water flux and porosity of $4 \mathrm{~A}$ zeolite/LDPE blend membrane is shown in Figure 7, in which the weight ratio of LDPE:zeolite and the temperature of cooling bath were fixed at 22.5:10 (w/w) and $25{ }^{\circ} \mathrm{C}$, respectively. DPE content of $56-80$ wt $\%$ were studied because it is difficult to form a 4A zeolite/LDPE membrane with desirable mechanical strength when DPE weight fraction is higher than 80 wt\%, while with DPE weight fraction lower than 56 wt\% the casting solution is too viscous for $4 \mathrm{~A}$ zeolite powder to incorporate into the system. From Figure $\mathbf{7}$, it is clearly evident that the water flux and porosity increases with increasing DPE content due to decreased viscosity and more diluent, which brought about the larger droplets generated by phase separation and thus the larger pores in membrane structure. This observation is in keeping with the finding of numerous previous L-L TIPS studies in the absence of particulate filler [26, 27].

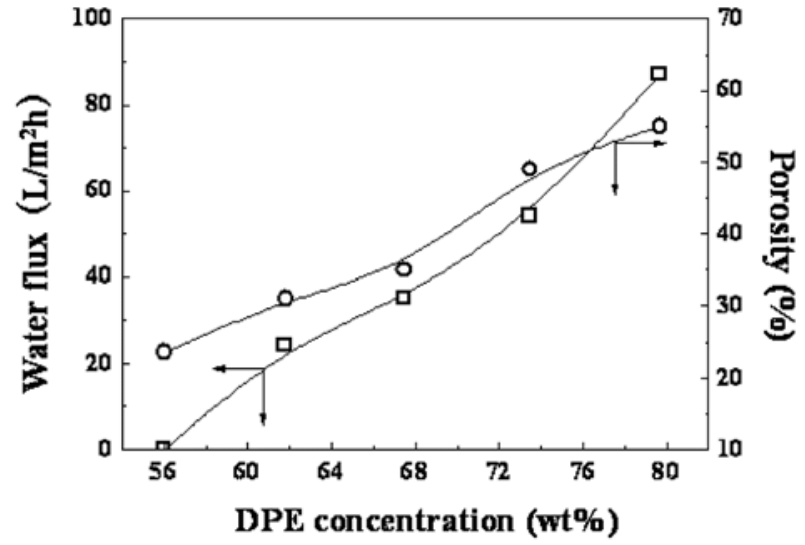

Figure 7: Effect of DPE content on the water flux and porosity of $4 \mathrm{~A}$ zeolite/LDPE blend membranes.

\section{Effect of Cooling Bath Temperature on Water Flux of 4A Zeolite/LDPE Blend Membranes}

Figure 8 shows the values of water flux and porosity of $4 \mathrm{~A}$ zeolite/LDPE blend membranes with different cooling bath temperature, the weight ratio of $4 \mathrm{~A}$ zeolite:LDPE:DPE were fixed at 10:22.5:67.5, respectively. It can be seen that the water flux of $4 \mathrm{~A}$ zeolite/LDPE blend membranes decreased with increasing the cooling bath temperature, but the

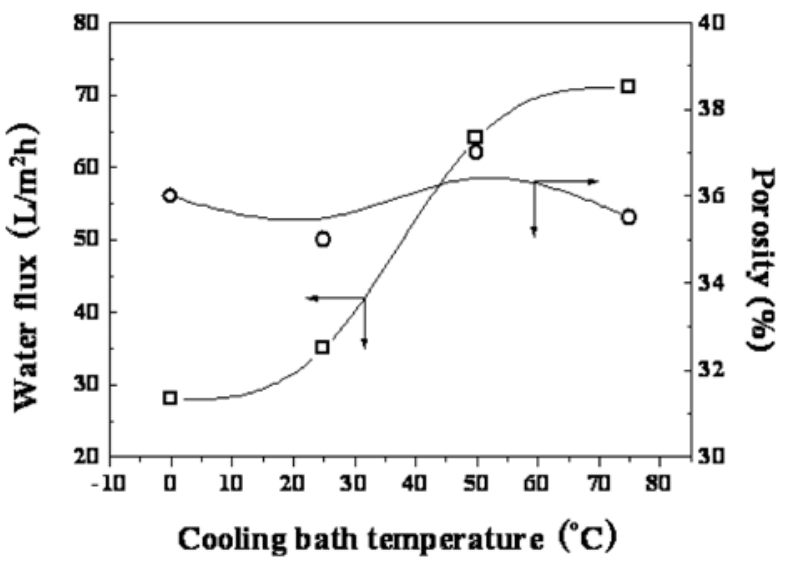

Figure 8: Effect of cooling bath temperature on the water flux and porosity of $4 \mathrm{~A}$ zeolite/LDPE blend membranes. 
porosity changed slightly. The higher water flux is corresponding to the larger pore size. The solidification of $4 \mathrm{~A}$ zeolite/LDPE/DPE system at higher cooling bath temperature means an decreasing cooling rate, which leads to a prolonged period for droplets to grow in the two phase liquid-liquid suspension [17]. So the pore size of $4 \mathrm{~A}$ zeolite/LDPE blend membranes increased with increasing the cooling bath temperature. While the nearly unchanged porosity is due to the same DPE content in the LDPE/zeolite/DPE mixtures, so, after extracting DPE, there should be a theoretical equal space left in the 4A zeolite/LDPE blend membranes.

\section{CONCLUSIONS}

Microfiltration membranes, 4A zeolite/LDPE, were firstly prepared by blending low density polyethylene and $4 \mathrm{~A}$ zeolite nanoparticles through thermally induced phase separation process with DPE as diluent. All the 4A zeolite/LDPE blend membranes showed good filmforming property and robust mechanical strength. The incorporation of $4 \mathrm{~A}$ zeolite particles greatly enhanced the connectivity of membrane pores and thus the water flux of $4 \mathrm{~A}$ zeolite/LDPE blend membranes which can be attributed to the gradually stronger DPE-zeolite affinity with the increase of the $4 \mathrm{~A}$ zeolite loading. On the other hand, the water flux and porosity increases with increasing DPE content due to the decreased viscosity. Further, with the increase of cooling bath temperature, the water flux of $4 \mathrm{~A}$ zeolite/LDPE blend membranes increased, but the porosity changed slightly which can be attributed to the longer growth time of droplets at a fixed diluent content.

\section{ACKNOWLEDGEMENTS}

This research was financially supported by the Industry-Academia Cooperation Innovation Fund Projects of Jiangsu Province (BY2012058), and the Innovation Fund for Small and Medium Technology Based Firms of Jiangsu Province (BC2010017).

\section{REFERENCES}

[1] Yang YF, Wan LS, Xu ZK. Surface Engineering of Microporous Polypropylene Membrane for Antifouling: A Mini-Review. J Adhes Sci Technol 2011; 25: 245. http://dx.doi.org/10.1163/016942410X520835

Hussain A, Al-Rawajfeh AE, Alsaraierh $\mathrm{H}$. Membrane bioreactors (MBR) in waste water treatment: a review of the recent patents. Recent Pat Biotechnol 2010; 4: 65. http://dx.doi.org/10.2174/187220810790069505

[3] Jiang JH, Zhu LP, Li XL, Xu YY, Zhu BK. Surface modification of PE porous membranes based on the strong adhesion of polydopamine and covalent immobilization of heparin. J Membr Sci 2010; 364: 194.

http://dx.doi.org/10.1016/j.memsci.2010.08.017
Ding HY, Tian Y, Wang LH, Liu BQ. Preparation of ultrahighmolecular-weight polyethylene membranes via a thermally induced phase-separation method. J Appl Polym Sci 2007; 105: 3355.

http://dx.doi.org/10.1002/app.26521

[5] Matsuyama H, Hayashi K, Maki T, Teramoto M, Kubota N. Effect of polymer density on polyethylene hollow fiber membrane formation via thermally induced phase separation. J Appl Polym Sci 2004; 93: 471. http://dx.doi.org/10.1002/app.20461

[6] Matsuyama $\mathrm{H}$, Okafuji $\mathrm{H}$, Maki T, Teramoto M, Kubota N. Preparation of polyethylene hollow fiber membrane via thermally induced phase separation. J Membr Sci 2003; 223, 119. http://dx.doi.org/10.1016/S0376-7388(03)00314-4

Matsuyama H, Kimb M, Lloyd DR, Effect of extraction and drying on the structure of microporous polyethylene membranes prepared via thermally induced phase separation. J Membr Sci 2002; 204: 413. http://dx.doi.org/10.1016/S0376-7388(02)00052-2

[8] Zhang M, Zhang CF, Yao ZK, Shi JL, Zhu BK, Xu YY, Preparation of high density polyethylene/polyethylene-blockpoly(ethylene glycol) copolymer blend porous membranes via thermally induced phase separation process and their properties. Chin J Polym Sci 2010; 28: 337. http://dx.doi.org/10.1007/s10118-010-9022-0

[9] Zhang J, Wang XL, Luo F, Li HL, Xu ZZ. Formation of low density polyethylene microporous membranes via thermally induced phase separation. (I) LDPE-18D/DPE system. Polym Mater Sci Eng 2004; 20: 174.

[10] Zhang J, Wang XL, Luo F, Xu ZZ, Wen JZ. Formation of low density polyethylene microporous membranes via thermally induced phase separation. (II) The effects of kinetic factors on the structures of microporous membranes. Polym Mater Sci Eng 2005; 21: 137.

[11] Li NN, Xiao CF, Preparation and properties of UHMWPE/SiO2 hybrid hollow fiber membranes via thermally induced phase separation-stretching method. Ira Polym J 2009; 18: 479.

[12] Yan L, Li YS, Effect of nano-sized $\mathrm{Al}_{2} \mathrm{O}_{3}$ particle addit ion on PVDF ultrafiltration membrane performance. J Membr Sci 2006; 276: 162.

http://dx.doi.org/10.1016/j.memsci.2005.09.044

[13] Xu GQ, Li XF, Lv XL. Effect of calcium carbonate on the structure of porous PVDF membrane in TIPS process. Polym Mater Sci Eng 2007; 23: 234.

[14] Cui AH, Liu Z, Xiao CF, Zhang YF. Effect of micro-sized $\mathrm{SiO}_{2}$-particle on the performance of PVDF blend membranes via TIPS. J Membr Sci 2010; 360: 259. http://dx.doi.org/10.1016/j.memsci.2010.05.023

[15] Maximous N, Nakhla G, Wan W, Wong K. Preparation, characterization and performance of $\mathrm{Al}_{2} \mathrm{O}_{3} / \mathrm{PES}$ membrane for wastewater filtration. J Membr Sci 2009; 341: 67. http://dx.doi.org/10.1016/i.memsci.2009.05.040

[16] Yang YN, Zhang HX, Wang P, Zheng QZ, Li J, The influence of nano-sized $\mathrm{TiO}_{2}$ fillers on the morphologies and properties of PSF UF membrane. J Membr Sci 2007; 288: 231. http://dx.doi.org/10.1016/j.memsci.2006.11.019

[17] Funk CV, Beavers BL, Lloyd DR. Effect of particulate filler on cell size in membranes formed via liquid-liquid thermally induced phase separation. J Membr Sci 2008; 325: 1. http://dx.doi.org/10.1016/j.memsci.2008.07.029

[18] Zhang CF, Bai YX, Sun YP, Gu J, Xu YY. Preparation of hydrophilic HDPE porous membranes via thermally induced phase separation by blending of amphiphilic PE-b-PEG copolymer. J Membr Sci 2010; 365: 216. http://dx.doi.org/10.1016/j.memsci.2010.09.007

[19] Gao JG, Yu MS, Li ZT. Nonisothermal crystallization kinetics and melting behavior of bimodal medium density 
polyethylene/low density polyethylene blends. Eur Polym 2004; 44: 1533.

http://dx.doi.org/10.1016/j.eurpolymj.2004.02.008

[20] Zhang CF, Yang L, Bai YX, Gu J, Sun YP. ZSM-5 filled polyurethaneurea membranes for pervaporation separation isopropyl acetate from aqueous solution. Sep Purif Technol 2012; 85: 8.

http://dx.doi.org/10.1016/j.seppur.2011.07.008

[21] Tretinnikov ON. Selective accumulation of functional groups at the film surfaces of stereo regular poly (methyl methacrylate). Langmuir 1997; 13: 2988. http://dx.doi.org/10.1021/la9700275

[22] Ji GL, Zhu LP, Zhu BK, Zhang CF, Xu YY. Structure formation and characterization of PVDF hollow fiber membrane prepared via TIPS with diluent mixture. J Membr Sci 2008; 319: 264. http://dx.doi.org/10.1016/j.memsci.2008.03.043

[23] Yan L, Li YS, Xiang CB, Preparation of poly(vinylidene fluoride)(pvdf) ultrafiltration membrane modified by nanosized alumina $\left(\mathrm{Al}_{2} \mathrm{O}_{3}\right)$ and its antifouling research. Polymer 2005; 46: 7701.

http://dx.doi.org/10.1016/j.polymer.2005.05.155
[24] Yu LY, Xu ZL, Shen HM, Hu Y. Preparation and characterization of PVDF-SiO 2 composite hollow fiber UF membrane by sol-gel method. J Membr Sci 2009; 337: 257. http://dx.doi.org/10.1016/j.memsci.2009.03.054

[25] Khoonsap S, Amnuaypanich S. Mixed matrix membranes prepared from poly(vinyl alcohol) (PVA) incorporated with zeolite 4A-graft-poly(2-hydroxyethyl methacrylate) (zeolite- $g$ PHEMA) for the pervaporation dehydration of water-acetone mixtures. J Membr Sci 2011; 367: 182. http://dx.doi.org/10.1016/j.memsci.2010.10.058

[26] McGuire KS, Laxminarayan A, Martula DS, Lloyd DR Kinetics of droplet growth in liquid-liquid phase separation of polymer-diluent systems: model development. J Colloid Interface Sci 1996; 182: 46.

http://dx.doi.org/10.1006/jcis.1996.0435

[27] McGuire KS, Laxminarayan A, Lloyd DR. Kinetics of droplet growth in liquid-liquid phase separation of polymer-diluent systems: experimental results. Polymer 1995; 36: 4951. http://dx.doi.org/10.1016/0032-3861(96)81620-X

Received on 18-07-2012

Accepted on 15-09-2012

Published on 04-10-2012

DOI: http://dx.doi.org/10.6000/1929-6037.2012.01.01.7

(c) 2012 Gu et al.; Licensee Lifescience Global.

This is an open access article licensed under the terms of the Creative Commons Attribution Non-Commercial License (http://creativecommons.org/licenses/by-nc/3.0/) which permits unrestricted, non-commercial use, distribution and reproduction in any medium, provided the work is properly cited. 